\title{
A curious course of an intramural anomalous left coronary artery from the pulmonary artery
}

\author{
Phillip S. Naimo, MD, Edward Buratto, MBBS, and Igor E. Konstantinov, MD, PhD, FRACS
}

\footnotetext{
From the Royal Children's Hospital; University of Melbourne; and Murdoch Children's Research Institute, Melbourne, Australia.

Disclosures: Authors have nothing to disclose with regard to commercial support.

Received for publication Oct 26, 2016; accepted for publication Oct 27, 2016; available ahead of print Dec 16, 2016.

Address for reprints: Igor E. Konstantinov, MD, PhD, FRACS, Royal Children's Hospital, Flemington Rd, Parkville, VIC 3029, Australia (E-mail: igor.konstantinov@rch.org.au).

J Thorac Cardiovasc Surg 2017;153:654-5

$0022-5223 / \$ 36.00$

Crown Copyright (C) 2016 Published by Elsevier Inc. on behalf of The American Association for Thoracic Surgery http://dx.doi.org/10.1016/j.jtcvs.2016.10.048
}

Anomalous left coronary artery from the pulmonary artery (ALCAPA) is a rare congenital cardiac malformation accounting for approximately 1 in 300,000 live births. ${ }^{1}$ The first reported child with ALCAPA was described by Russian pathologist Alexei Ivanovich Abrikosov in 1911, when he described postmortem "a left ventricular aneurysm with anomalous origin of the left coronary artery from pulmonary artery in a 5-month old child." 2 A comprehensive clinical description was given in 1933 by American physicians Edward Bland, Paul Dudley White, and Joseph Garland. ${ }^{3}$

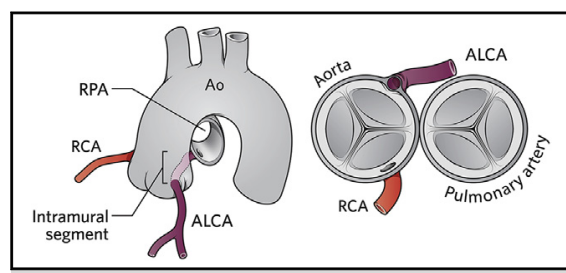

Anomalous origins of the left coronary artery from the right pulmonary artery.

Central Message

Coronary transfer and unroofing are important techniques for managing rare cases of intramural anomalous left coronary artery from the right pulmonary artery.

See Article page 648.

Thus, a typical clinical presentation is often referred to today as Bland-White-Garland syndrome.
A

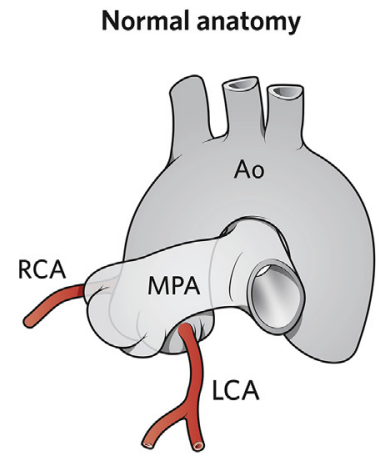

Intramural ALCA from junction of MPA and RPA

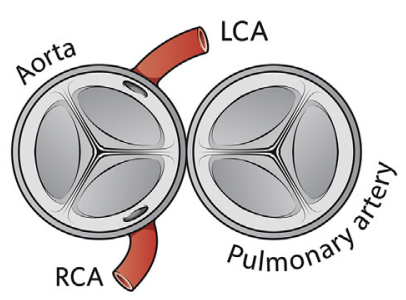

B
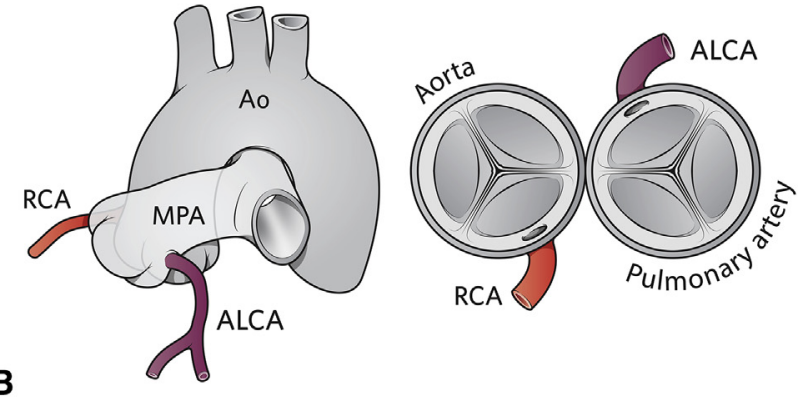

Intramural ALCA from RPA
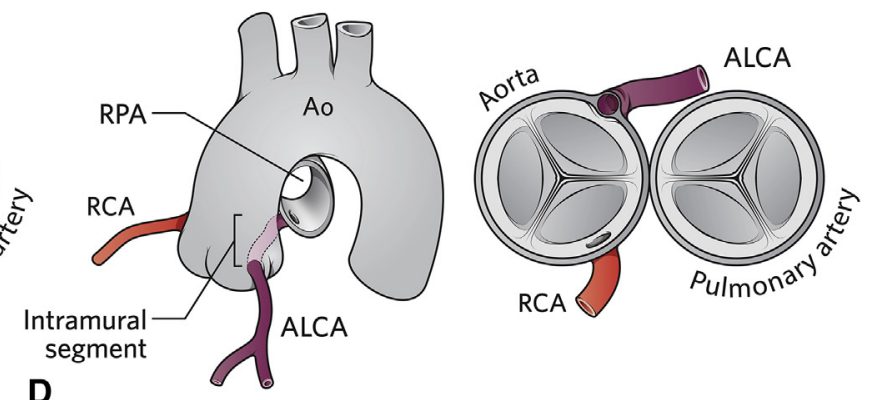

C

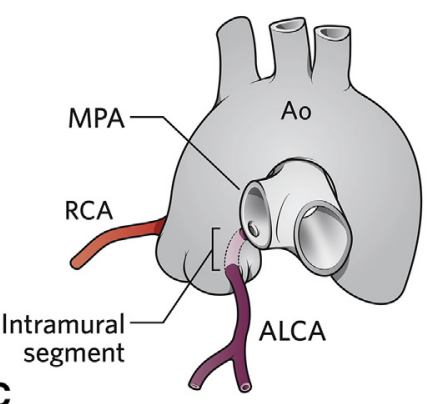

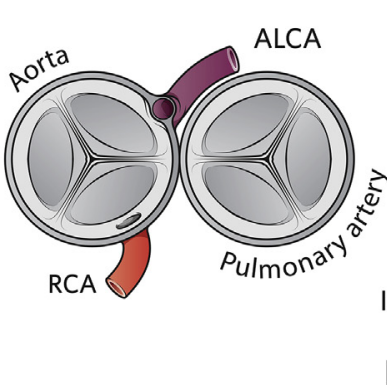

D
ALCA from MPA

FIGURE 1. Anomalous left coronary artery origin from the pulmonary artery and its relation to normal anatomy of the great arteries. A, Normal anatomy. B, ALCA from MPA. C, Intramural ALCA from the junction of MPA and RPA. D, Intramural ALCA from RPA. Ao, Aorta; RCA, right coronary artery; $M P A$, main pulmonary artery; $L C A$, left coronary artery; $A L C A$, anomalous left coronary artery; $R P A$, right pulmonary artery. 
To understand the pathologic anatomy of this rare anomaly, one should appreciate that the normal ascending aorta and main pulmonary artery (PA) are almost perpendicular to one another (Figure 1, A). In ALCAPA, the left coronary artery (LCA) most commonly originates from the posterior facing sinus of the PA (Figure $1, B$ ) in close proximity to where the normal origin of the LCA would be. Nonetheless, the LCA can come from any part of the main PA or its branches, albeit rarely. If the LCA comes from the junction of the main PA and right PA (Figure 1,C) or the right PA (Figure 1, D), it may have an intramural aortic course. This is an exceedingly rare association. The literature is limited to a few case reports and small series. ${ }^{4-9} \mathrm{~A}$ remarkable article by Zhang and colleagues ${ }^{10}$ describes 10 children with intramural course of the ALCAPA arising from the right PA. It is fascinating that 10 children with such rare anomaly had surgery over a relatively short period of 7 years, likely owing to the fact that the report comes from one of the largest volume institutions from Beijing, China. Consider that in our institution only 1 of 42 children undergoing operation for ALCAPA over a 35-year period had intramural course of an anomalous coronary artery. ${ }^{11}$ Furthermore, our experience was similar to that of others. $^{4-8}$

The patients studied by Zhang and colleagues ${ }^{10}$ were older at the time of repair compared with most modern reports, which likely explains a higher proportion of children with left ventricular aneurysms and relatively high mortality. The surgical technique of coronary artery transfer and unroofing appears to provide reliable reperfusion of the myocardium and resulted in improvement of the left ventricular function. Coronary unroofing is, indeed, a simple and reliable technique and could be safely used even in neonates with intramural coronary arteries. ${ }^{12}$ Due to the close resemblance to normal anatomy, the intramural course of the coronary artery commonly remains undiagnosed on preoperative imaging. The intramural course should be suspected in all children with ALCAPA originating from the right $\mathrm{PA}^{6}$ to avoid damage to the intramural segment. The value of opening the main PA first to identify the origin of the LCA cannot be overemphasized. As long as the coronary artery is not allowed to kink during reimplantation, the unroofing is easy and likely to be the best option. ${ }^{4}$ The technique described by Zhang and colleagues ${ }^{10}$ is a valuable addition to armamentarium of any cardiothoracic surgeon who deals with congenital coronary anomalies.

\section{References}

1. Cowles RA, Berdon WE. Bland-White-Garland syndrome of anomalous left coronary artery arising from the pulmonary artery (ALCAPA): a historical review. Pediatr Radiol. 2007;37:890-5.

2. Abrikosov A. Aneurysma des linken Herzventrikels mit abnormer Abgangsstelle der linken Koronararterie von der Pulmonalis bei einem funsonatlichen Kinde. Virchows Arch Pathol Anat Physiol Klin Med. 1911;203:413-20.

3. Bland EF, White PD, Garland J. Congenital anomalies of the coronary arteries: report of an unusual case associated with cardiac hypertrophy. Am Heart J. 1933; 8:787-801.

4. Kumar TKS, Sinha P, Donofrio MT, Jonas RA. Anomalous left coronary artery from the right pulmonary artery with aortic fusion. J Thorac Cardiovasc Surg. 2012;143:505-7.

5. Turley K, Szarnicki RJ, Flachsbart KD, Richter RC, Popper RW, Tarnoff H. Aortic implantation is possible in all cases of anomalous origin of the left coronary artery from the pulmonary artery. Ann Thorac Surg. 1995;60:84-9.

6. Goldberg SP, Mitchell MB, Campbell DN, Tissot C, Lacour-Gayet F. Anomalous left coronary artery from the pulmonary artery with an intramural course within the aortic wall: report of 3 surgical cases. J Thorac Cardiovasc Surg. 2008;135: 696-8.

7. Adachi I, Kagisaki K, Yagihara T, Hagino I, Ishizaka T, Kobayashi J, et al. Unroofing aortic intramural left coronary artery arising from right pulmonary artery. Ann Thorac Surg. 2008;85:675-7.

8. Barbero-Marcial M, Tanamati C, Atik E, Ebaid M, Jatene A. Anomalous origin of the left coronary artery from the pulmonary artery with intramural aortic route: diagnosis and surgical treatment. J Thorac Cardiovasc Surg. 1999; 117:823-5

9. Marshall CD, Weigand J, Sambatakos P, Hayes DA, Chen JM, Quaegebeur JM, et al. Repair of anomalous left coronary artery from the right pulmonary artery: a series of nine cases. World J Pediatr Congenit Heart Surg. 2015;6:382-6.

10. Zhang H, Cheng P, Jin G, Han D, Luo Y, Li J. Surgical strategies for anomalous origin of the left coronary artery from the right pulmonary artery with an intramural aortic course: a report of 10 cases. J Thorac Cardiovasc Surg. 2017;153: 648-53.

11. Naimo PS, Fricke TA, d'Udekem Y, Cochrane AD, Bullock A, Robertson T, et al. Surgical intervention for anomalous origin of left coronary artery from the pulmonary artery in children: a long-term follow-up. Ann Thorac Surg. 2016;101: 1842-8.

12. Fricke TA, Bulstra AE, Naimo PS, Bullock A, Robertson T, d'Udekem Y, et al Excellent long-term outcomes of the arterial switch operation in patients with intramural coronary arteries. Ann Thorac Surg. 2016;101:725-9. 